\title{
No hard borders for humans
}

\author{
Radiocarbon dates from Spain put anatomically modern humans in southernmost Europe 10,000 years earlier than \\ previously thought, diminishing the case for late survival of Neanderthals in the region.
}

\section{Katerina Douka}

$\mathrm{N}$ o matter how uninviting or impenetrable some of the world's regions may seem, it is now known that anatomically modern humans (AMH) have been able to inhabit most of them since the last Ice Age, and there appear to have been few, if any, 'hard' biogeographical borders that applied to our species. One of the last borders to remain, both conceptually and physically, is described by the 'Ebro frontier' hypothesis ${ }^{1-3}$, which states that the Ebro river basin in northwest Spain (Fig. 1) was a major divide between the first dispersing $\mathrm{AMH}$ populations colonizing Iberia from the north and the southern Neanderthals that had been in the region since the Middle Pleistocene. Writing in this issue of Nature Ecology and Evolution, Cortés-Sánchez et al. ${ }^{4}$ present evidence from Bajondillo Cave that questions this frontier hypothesis by suggesting that $\mathrm{AMH}$ were at the southwestern edge of Iberia-well beyond the Ebro basinas early as 43,000 years ago (43 ka), contemporaneous with other modern human occupations in Western Europe.

The Ebro frontier hypothesis was formulated as an attempt to explain the seemingly prolonged survival of Neanderthals at sites south of the Ebro basin and the apparent delay in the establishment of AMH in the same region. It has been difficult to disentangle whether one observation was the causal factor or the effective outcome of the other, whether this pattern is the result of significant differences between two biogeographic zones (Eurosiberian and Mediterranean), or whether this pattern is simply an artifact of poor chronologies caused by a small number of sites and the unfavourable preservation conditions for organic samples in most of Iberia. These options are not mutually exclusive, and, in unravelling them, prehistorians are faced with the dearth of human fossils from the region. Where there are human fossils, these are rarely dated directly and reliably. Therefore, pinpointing the locations of AMH and Neanderthals at a given time depends on the analyses and absolute dating of the material

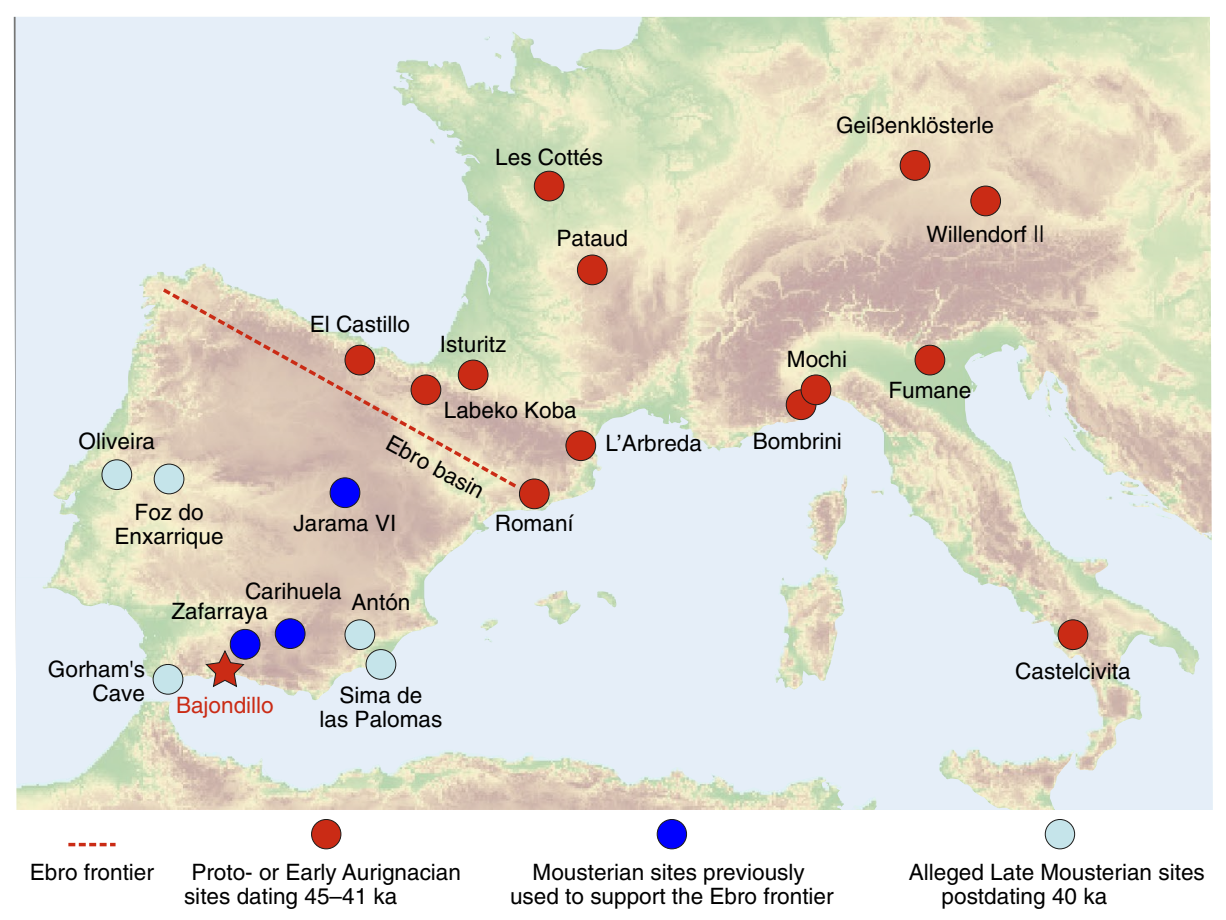

Fig. 1 | Map with locations of Proto- and Early Aurignacian and late Mousterian sites. Chronometric ages are given in ka. Basemap credit: European Environment Agency (EEA).

culture, stone tools in particular, left behind by these species. Associating these assemblages with those left elsewhere relies on technological and typological similarities between them.

Piecing the various data sources together, researchers have previously reconstructed the scenario as follows: north of the Ebro, AMH manufactured 'Protoaurignacian' and 'Early Aurignacian' toolkits and produced bone points and shell beads as early as 45-42 ka; however, such assemblages have not been found in southern Iberia. There, instead, Neanderthals who produced 'Mousterian' toolkits were thought to persist as late as $34 \mathrm{ka}$, if not later, and $\mathrm{AMH}$ that manufactured different Aurignacian assemblages (known as 'Evolved Aurignacian' or 'Aurignacian II') appeared only after $\sim 35 \mathrm{ka}$.

Bajondillo Cave followed the predicted pattern, with late Mousterian layers giving way to Evolved Aurignacian ones-until now. Cortés-Sánchez et al. ${ }^{4}$ re-analyzed stone tool assemblages from the site and dated the soil containing them, and they also dated charcoal and shells found in the same layers. Their analysis suggests that the stone tools from layer $\mathrm{Bj} / 13$ are in fact of Protoor Early Aurignacian affinity, with strong links to the overlying layer $\mathrm{Bj} / 11$ (Evolved Aurignacian). Both layers are assumed to have been made by AMH. The evidence also attests to a clear break with the Mousterian assemblage from underlying layer $\mathrm{Bj} / 14$, attributed to Neanderthals. On the basis of 17 new radiocarbon dates and a Bayesian statistical model, the authors place the end of the Neanderthal-associated Mousterian at Bajondillo at around $46 \mathrm{ka}$, the start of the AMH-associated early Aurignacian between $\sim 43$ and $41 \mathrm{ka}$, and the start of the Evolved Aurignacian at $\sim 38 \mathrm{ka}$. These age estimates 
therefore place modern humans in Iberia at a very early date, refuting late Neanderthal persistence at the site. They also closely match those reported recently for sites in northern Spain ${ }^{5}$, but, crucially, Bajondillo is south of the Ebro river basin.

Whether the Bajondillo Bj/13 layer represents one-off modern human penetration from the north inland into an otherwise dense late-Neanderthal landscape further south or whether completely different dispersal patterns of AMH ought to be considered, such as littoral or riverine, is difficult to interpret.

Chronology is at the heart of the issue. Wood et al. ${ }^{6}$ reported that two-thirds of the chronometric data associated with Late Neanderthals in Iberia is highly questionable owing to the lack of rigorous analytical methodologies during radiocarbon dating. They conclude that evidence for the late survival of Neanderthals is limited and that the case remains to be proven. The analytical techniques used for the new Bajondillo chronology are not as rigorous as they could be for some sample types (such as charcoal), and the radiocarbon determinations should be considered minimum ages at best. This would naturally move both the Mousterian and Aurignacian layers back in time, making them even older.

In a similar manner to the Bajondillo case, other sites previously thought to document the late persistence of Neanderthals in southern Iberia are being re-evaluated using modern chronometric methodologies, which have rendered these sites substantially older ${ }^{6}$ (Fig. 1). Mousterian sites now consistently date between 40 and $45 \mathrm{ka}$ and older ${ }^{7,8}$. A few sites ${ }^{9}$ remain cases for a possible later Neanderthal persistence south of the Ebro after $40 \mathrm{ka}$ (Fig. 1), but these sites' chronologies and lithic sequences are not without problems. Current data seem to suggest that if Neanderthals were present later than $45-40 \mathrm{ka}$, then they were thin on the ground and scattered across the peninsula in isolated groups.

Still, the ever-diminishing number of late Neanderthal occurrences does not directly explain the absence of early modern human sites in southern Iberia. Evidence for some early Aurignacian occurrences is slowly coming to light, but to fully explore whether the pattern is true, more reliably dated and sufficiently diagnostic assemblages are badly needed. If the difficulty in assigning certain lithic collections to the earliest phases of the Upper Palaeolithic was due to preconceptions prevailing across the Iberian Palaeolithic research landscape in the last 25 years, perhaps the re-valuation by Cortés-Sánchez et al. ${ }^{4}$ will inspire other researchers to revisit old 'indeterminate' assemblages and renew efforts to diagnose Upper Palaeolithic assemblages more readily and robustly.

In the wake of ample evidence for human admixture, simply assigning lithic assemblages to one human group or another is becoming increasingly problematic and complex. For this reason, state-of-the-art biomolecular methodologies characterising human presence beyond the strict dichotomies imposed by lithic studies must be considered. Existing human fossils, fauna and site sediments ought to be analysed exhaustively. Despite organic preservation hurdles, consistent and persistent attempts to retrieve ancient DNA from bones and sedimentary columns or the use of collagen fingerprinting (ZooMS) on unidentifiable bone fragments for discovering human remains should be part of every Palaeolithic archaeologist's toolkit.

\author{
Katerina Douka ${ }^{1,2}$ \\ ${ }^{1}$ Max Planck Institute for the Science of Human \\ History, Jena, Germany. ${ }^{2}$ School of Archaeology, \\ University of Oxford, Oxford, UK. \\ e-mail:douka@shh.mpg.de
}

Published online: 21 January 2019

https://doi.org/10.1038/s41559-018-0795-9

References

1. Zilhão, J. in le Portugal in El Origen del Hombre Moderno en el Suroeste de Europa (ed Cabrera, V.) 127-145 (Universidad Nacional de Educación a Distancia, Madrid, 1993).

2. Zilhão, J. in Neanderthals on the Edge (eds Stringer, C.B., Barton, R.N.E. \& Finlayson, J.C.) 111-121 (Oxbow Books, Oxford, 2000).

3. Zilhão, J. in The Mediterranean from 50,000 to 25,000 BP: Turning Points and New Directions (eds Camps, M. \& Szmidt, C.) 293-312 (Oxbow Books, Oxford, 2009).

4. Cortés-Sánchez, M. et al. Nat. Ecol. Evol. https://doi.org/10.1038/ s41559-018-0753-6 (2019).

5. Marín-Arroyo, A. B. et al. PLoS One 13, e0194708 (2018).

6. Wood, R. E. et al. Proc. Natl. Acad. Sci. USA 110, 2781-2786 (2013).

7. Galván, B. et al. J. Hum. Evol. 75, 16-27 (2014).

8. Kehl, M. et al. Quat. Res. 90, 180-200 (2018).

9. Zilhão, J. et al. Heliyon 3, e00435 (2017).

Competing interests

The author declares no competing interests. 